DIEGO MIER Y TERÁN GIMÉNEZ CACHO

DIRECTOR

INNOVANDO LA TRADICIÓN

COLECTIVO $1050^{\circ}$

OAXACA, MÉXICO

DIEGO@INNOVANDOLATRADICION.ORG

KYTHZIA BARRERA SUÁREZ

DIRECTORA

INNOVANDO LA TRADICIÓN

COLECTIVO $1050^{\circ}$

OAXACA, MÉXICO

KYTHZIA@1050GRADOS.COM

\section{Diseño, territorio y narrativa. Nuevos futuros a través del barro}

Design, territory and narratives.

New futures through pottery

Resumen. Compartimos las preguntas e intenciones que han guiado nuestro caminar como diseñadores en los pueblos rurales de Oaxaca, México, durante los últimos quince años. Compartimos los retos y aprendizajes que nos han ofrecido los artesanos del barro con quienes trabajamos, a quienes consideramos nuestros maestros y los diseñadores originarios de México. Presentamos también algunas reflexiones sobre el papel del Diseño en las narrativas dominantes que conforman el mundo, así como unas rutas de escape para descolonizar al Diseño y convertirlo en una práctica significativa para Latinoamérica, a partir de abandonar, paradójicamente, el territorio habitual del Diseño y habitar sus márgenes.

Palabras clave: alfarería, artesanía, barro, narrativa, territorio

Abstract. In this article we share the questions and intentions that have guided our journey as designers in the rural villages of Oaxaca, Mexico, during the last 15 years. We share the challenges and lessons that the clay artisans with whom we work, have given us. We consider them our teachers and the original designers from Mexico. We also present some reflections on the role of design in shaping the dominant narratives that give shape to the world, as well as escape routes to decolonize design into a truly significant practice for Latin America by, paradoxically, abandoning the territory of design to inhabit its margins.

Keywords: clay, crafts, narratives, pottery, territory
Fecha de recepción: 05/07/2019

Fecha de aceptación: 02/11/2019

Cómo citar: Mier y Terán Giménez Cacho, D.

y Barrera Suárez, K. (2019). Diseño, territorio y

narrativa. Nuevos futuros a través del barro.

RChD: creación y pensamiento, 4 (7), 1-13

DOI: 10.5354/0719-837X.2019.53823 


\section{Introducción}

La intención de este artículo es compartir algunas de las preguntas e intenciones que han guiado nuestro caminar como diseñadores en los pueblos de Oaxaca, México, durante los últimos quince años. Este caminar inicia con una fascinación por los objetos anónimos, humildes y funcionales que los diferentes pueblos originarios han creado durante la historia sin la necesidad de diseñadores profesionales.

Nuestro interés por el trabajo de los artesanos, específicamente las y los alfareros de Oaxaca, surge en parte como respuesta a las diferentes crisis civilizatorias que enfrentamos (ambiental, económica, social, espiritual, etc.). Surge también de nuestra convicción sobre el poder transformador del Diseño, por un lado y, por el otro, de la certeza de que para que este poder se actualice es necesario desarrollar prácticas verdaderamente significativas y apropiadas a nuestro contexto geográfico e histórico, lo cual implica abandonar los territorios familiares de lo que conocemos como "Diseño".

\section{El mapa y el territorio}

Pensar el Diseño a través de la noción de territorio nos resulta especialmente útil para mapear la situación actual de la disciplina y sus efectos en nuestro país. Analizar el territorio geográfico, el territorio psicohistórico local y el territorio de la disciplina, nos permite entender dónde estamos, desde dónde actuamos y a dónde queremos movernos.

Empecemos entonces por analizar el mapamundi como un objeto de diseño. Las historias y los mitos que una cultura cuenta condicionan cómo esta percibe y se relaciona con la realidad. Nuestra sociedad ha crecido entendiendo el mundo a través de la proyección de Mercator, elaborada en el S. XVI y aún utilizada ampliamente, a pesar de sus enormes distorsiones y sesgos. Ningún mapa es una representación objetiva del mundo, sino una representación de una manera de ver el mundo, una manera de narrar el mundo.

El mapamundi de Mercator pone en acción una manera específica de ver el mundo, de narrarlo, y a la vez define cómo lo entendemos y por lo tanto cómo nos relacionamos con él. El mapa es, literal y metafóricamente, un diseño del mundo.

Confundimos mapa con territorio y pensamos, por ejemplo, que el Norte está arriba y el Sur abajo, a pesar de que el universo no tiene arriba y abajo. Pensamos que América está a la izquierda, Europa en el centro y Oceanía en el margen, a pesar de que el globo terráqueo es redondo. Estas nociones estéticas y simbólicas tienen consecuencias profundas al determinar la manera en cómo nos narramos a nosotros mismos (en este caso desde una mirada externa), y se materializan en decisiones políticas, flujos migratorios, nacionalismos, deseos, sueños y aspiraciones.

A través del mapamundi común, una herramienta diseñada y aparentemente inocente o neutral, introyectamos la visión eurocentrista del mundo, por decirlo de alguna manera. No es nada nuevo mencionar la no neutralidad del mapa, y debemos entonces preguntarnos ¿por qué esta visión del mundo sigue siendo la hegemónica? ¿queremos que siga así? ¿quién se beneficia con este acomodo? Hace varios años, Quino, en voz de Mafalda, lo explicó con claridad meridiana: (el mapa) "es un truco psicológico de los que creen estar arriba para que los que creemos estar abajo, sigamos creyendo que estamos abajo". 
Eduardo Galeano (1998) también nos advierte: “El mapa miente. La geografía tradicional roba el espacio, como la economía imperial roba la riqueza, la historia oficial roba la memoria y la cultura formal roba la palabra".

Es importante reconocer cómo desde el Diseño participamos en la conformación del mundo. A través de las metáforas implícitas en las herramientas que utilizamos -los productos que los diseñadores traen al mundo, las interfaces con la realidad-se configuran nuestras nociones de territorio, de riqueza y pobreza, de lo que es deseable o lo que no, de la memoria y la historia, de la palabra, el lenguaje, nuestros cuerpos y ritmos. Estas son metáforas fácilmente colonizadas por las narrativas dominantes, cuando no son hechas de maneras conscientes.

En Latinoamérica, el Diseño ha sido, tal vez desde su origen y con contadas excepciones, tanto una disciplina colonizada por la narrativa del Norte global como una herramienta colonizadora, la que replica, amplifica y hace deseables el conjunto de valores de dicha narrativa. Los diseñadores $-y$, vale decir, también la academia- hemos asumido las nociones de progreso validadas por las potencias industriales y con estas los criterios estéticos que le acompañan, así como las preguntas que nos planteamos. El Diseño latinoamericano se ha dedicado, por muchos años, a responder las preguntas de otros. Creemos que es vital que los diseñadores entendamos nuestro oficio desde esta perspectiva amplia, como constructores de la cultura y la civilización, desde una mirada crítica y politizada, asumir las consecuencias a largo plazo de los productos que generamos (espacios, objetos, mensajes, sistemas) más allá de su éxito comercial o artístico. La estética como ética.

\section{iPhone}

Para reconocer el territorio del Diseño, vale la pena hacer zoom-in en una parte del mapa (el centro en este caso), para observar uno de los íconos más obvios de lo que ordinariamente se entiende por diseño: el iPhone. Vale la pena analizar y deconstruir el mensaje del iPhone, pues para muchos, dentro y fuera del Diseño, este objeto marca la ruta a seguir. ¿Por qué hay gente que acampa fuera de las tiendas de Apple para comprar la última versión de un aparato electrónico? ¿Qué nos dice un objeto tan preciado y extendido como el iPhone de aquello que nos parece importante, valioso y deseable como civilización? ¿Qué mitos materializa?

¿Qué nos dice su "diseño minimalista" de formas suaves, redondeadas? Además de una respuesta formal a criterios técnicos, ergonómicos y mercadológicos, son una puesta en escena de los valores de la sociedad occidental: la eficiencia, el control y la desconexión con la tierra. Su cualidad aséptica, impecable, aparentemente neutral (global, nos dicen), hace un objeto desconectado de su origen, sin marca alguna de quién o dónde fue fabricado. El iPhone se esfuerza, con su diseño “ligero”, en ocultar su peso real: el enorme costo ambiental y humano de su producción. Es un objeto totalmente deslocalizado, desterrado, sin raíz. La fluidez en el diseño, tanto del objeto en sí como de la interfaz, alimenta la ilusión de controlar el mundo con una mano (hoy sabemos que, en realidad, son los corporativos detrás de la herramienta quienes nos controlan) y fomenta la sensación del individuo de ser el centro del universo. El iPhone es, junto al automóvil o la botella de agua, la quintaesencia del individualismo neoliberal y la encarnación de los mitos fundacionales de los EUA. Un googleo veloz a la historia del Diseño nos deja ver cómo la estética del iPhone da continuidad a la utopía aerodinámica y plástica de la posguerra estadounidense. 
1. Ver https://hooktube.com/TwA7c_rNbJE
Es escalofriante observar cómo los diseñadores hemos introyectado una visión de progreso basado en la glorificación de la tecnología y la ciencia, enclavada en la acumulación de poder y riqueza. Reproducimos acríticamente el mismo sueño desde los años 50 como si nada hubiera cambiado, como si no nos hubiéramos enterado de que el crecimiento lineal e infinito está condenado al fracaso. El Diseño -los diseñadores, mejor dicho- ha sido prisionero de una utopía tecno-futurista congelada en el tiempo que se nos ha vendido como inevitable. La "Magic Highway"1 es todavía un ideal para muchos diseñadores que sueñan los sueños de otros.

La visión de lo deseable no solo se expresa en nuestros teléfonos, automóviles, casas o ciudades, también se ha introyectado, por ejemplo, en nuestros propios cuerpos y en cómo los concebimos.

Un cuerpo bello y deseable es aquel similar al iPhone: fit, limpio y eficiente, sin vello, sin grasa, removido del paso del tiempo, inalterable y siempre joven. Cuerpos-máquina, cuerpos dóciles.

El problema no es la estética, por supuesto, sino las consecuencias de sostener una narrativa uniformadora y anacrónica: por un lado, la invisibilización constante de la gran diversidad que existe en el mundo -la base de la vida-, la invisibilización de lo que realmente existe, de lo que nos hace humanos, a favor de un ideal homogéneo y de control corporativo. Por otro lado, el altísimo costo humano, ambiental y espiritual que implica mantener esa ilusión, lo que deriva en el calentamiento global, la extinción masiva de especies, los constantes conflictos entre estados y naciones indígenas, la militarización de los gobiernos, o la pérdida de diversidad lingüística.

\section{Diseño}

El hecho de mapear el territorio actual del diseño significa reconocer sus metodologías, objetivos, ideales estéticos, lenguaje y población a la que se dirige, entre otros aspectos. La descripción detallada de ese territorio será motivo de otro artículo, baste decir que observamos una disciplina bastante homogénea en estos campos, una práctica dependiente del poder, que genera productos y servicios para un porcentaje de la población muy reducido, y cuyos criterios de éxito se centran en obtener fama y dinero.

El Diseño se ha mantenido anclado a una zona muy reducida del territorio de sus posibilidades, lo que lo ha convertido en "vector y escaparate" de la ideología del progreso, es al mismo tiempo la gasolina de la sociedad de consumo y lo que la vuelve deseable (Grupo Marcuse, 2006).

Afortunadamente, el Diseño, desde su concepción más amplia como una habilidad humana para "transformar situaciones existentes en situaciones preferidas", como los describe Herbert Simon (1996), también nos presenta algunas sanas alternativas.

El "Dymaxion map" de Buckminster Fuller, como ejemplo de diseño que busca replantear el mundo-sistema desde una perspectiva flexible y ecocéntrica, nos aporta ricas líneas de escape. No hay más que verlo para sentir una brisa de aire fresco e intuir las posibilidades y beneficios (temores también) que un replanteamiento radical de nuestras herramientas y sistemas puede aportar. Nos preguntamos: ¿qué modelos alternativos tenemos para entender el territorio del Diseño? ¿Qué imágenes o metáforas nos pueden ayudar a replantear y descolonizar los presupuestos del Diseño? ¿Cuál sería el Dymaxion map del Diseño mexicano o latinoamericano que nos permitiría replantear la práctica desde una perspectiva radicalmente diferente? 


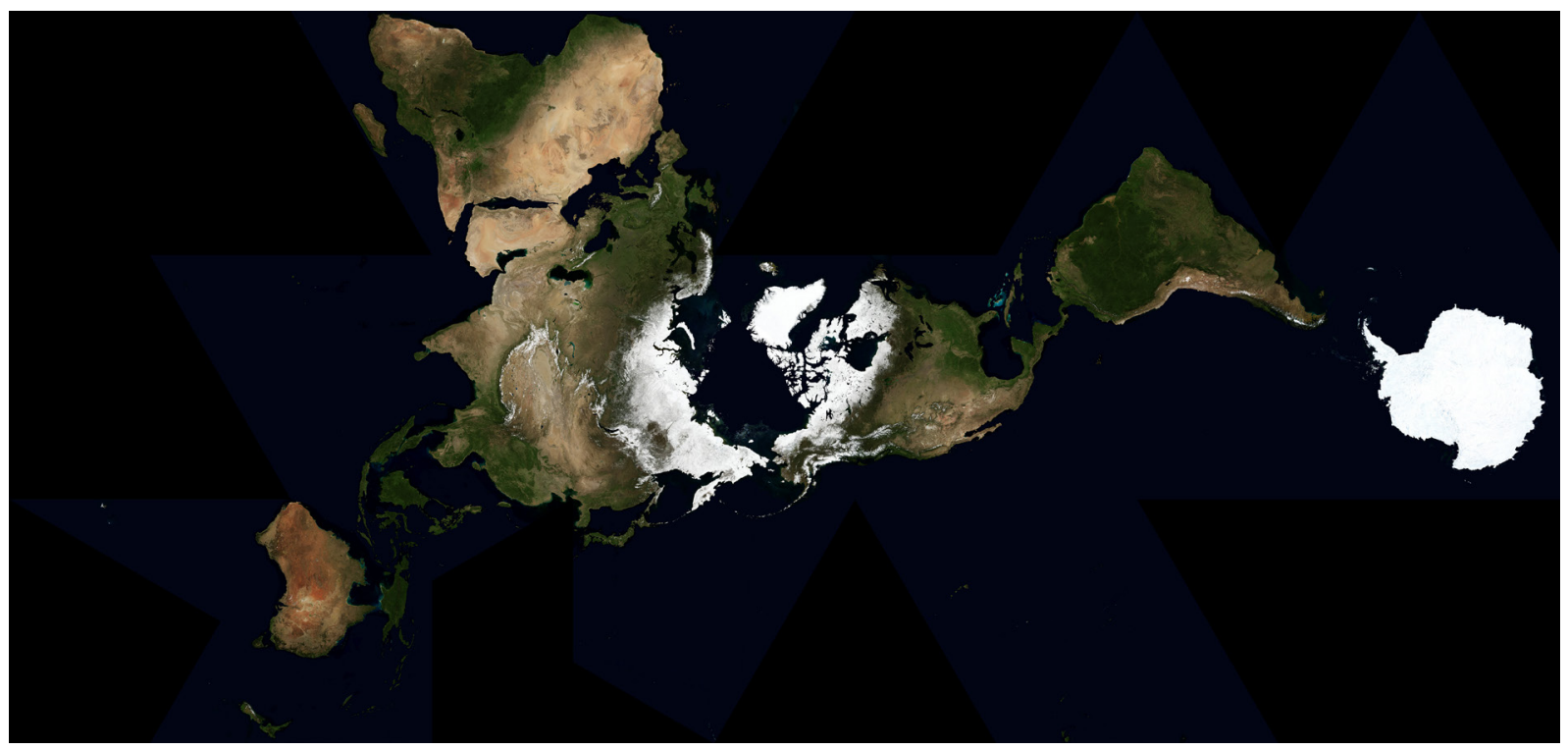

Para encontrar respuestas, hace quince años nos echamos a andar fuera del territorio conocido, fuera del centro y hacia los márgenes, adentrándonos en las áreas poco exploradas de lo que podríamos llamar la producción simbólica y material de los pueblos rurales e indígenas de México: eso que queda fuera de la categoría "diseño", por no provenir de profesionales urbanos, aunque sin duda ha sido diseñado con maestría como herramientas para la vida. Revisamos la mal llamada "artesanía", no los objetos suntuosos para coleccionistas, sino aquellos objetos funcionales y humildes que concebimos como el diseño original de la región. En ese camino nos encontramos con un tazón, o taza chocolatera, como la Ilaman en Oaxaca.

\section{Un tazón}

La alfarería es el oficio de dar vida a la tierra. Amando Pedro, San Bartolo Coyotepec

Un tazón de barro nos ha permitido vislumbrar una historia radicalmente distinta, diametralmente opuesta a la del progreso tecno-industrial y a la sociedad de mercado, nos ha permitido replantear y resignificar nuestra práctica como una basada en la reconexión entre las personas y con la tierra. Al igual que el mapa de Buckminster Fuller, un humilde tazón de barro, como metáfora de otras formas de vida, nos aporta un camino posible, pistas y ventanas, para la descolonización del Diseño en Latinoamérica y por extensión de nuestras historias, siempre y cuando estemos dispuestos a escuchar la voz de la tierra, que habla en silencio.

¿Qué nos ha enseñado el barro? Un tazón tradicional de barro es un contenedor de historia. En Oaxaca, todos los días se bebe chocolate en el mismo tipo de taza que se usaba hace dos mil años en rituales sagrados y cotidianos. Así, cada mañana al beber chocolate conectamos con nuestras raíces. Un tazón es también, por supuesto, economía. La alfarería provee sustento para miles de personas en setenta pueblos distribuidos en todo el estado de Oaxaca. El barro se vende y se compra, casi siempre con dinero, a veces con trueque por maíz, arroz, frijol o gallinas.

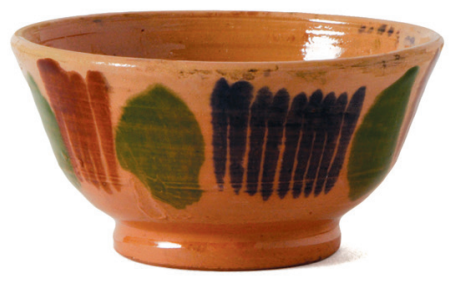

Figura 1. “Dymaxion Map”, Buckminster Fuller, 1943. No intentes cambiar un sistema, construye uno nuevo que haga que el anterior se vuelva obsoleto. Fuente: Buckminster Fuller.

Figura 2. Taza chocolatera, elaborada en San Martín Mexicapan, Oaxaca, por la familia Chávez, 2008. Foto de los autores. 


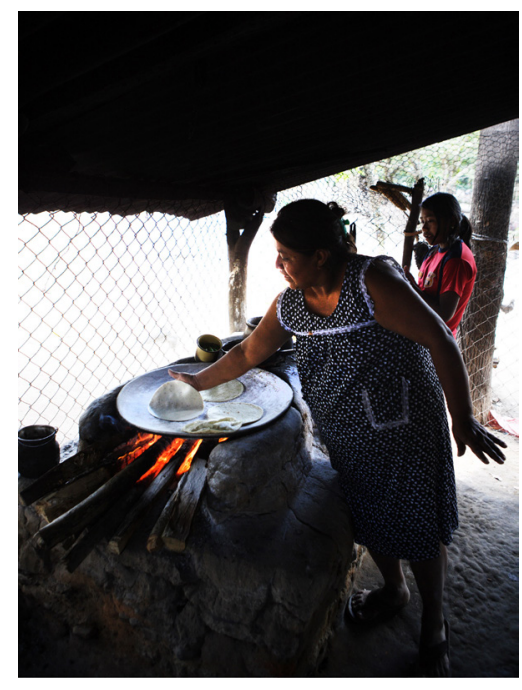

Figura 3. Mujer alfarera cocinando tortillas en La Guadalupe, Guerrero, 2011. Foto: Paris Barrera. Mi comal no es solo una artesanía, ni una obra de arte, es una herramienta de trabajo para otros. Sin el comal no hay tortillas y sin tortillas no comemos. Catalina Ortiz Guerrero, Santa María Atzompa.
Además de asegurar la subsistencia a través del intercambio, el comercio local, sino siempre al menos en muchos casos, no tiene como motor fundamental o prioritario la acumulación de capital, sino la necesidad de establecer relaciones.

Como ejemplo: es común que una alfarera a la que se le compran piezas regale un pilón (un extra) al cliente, que puede llegar a ser de hasta un $20 \%$ del valor de una compra. Una práctica que, desde el punto de vista empresarial, es poco eficiente, pero que, pensada desde el placer de establecer y honrar una relación humana, del compartir, tiene total sentido.

Esta es la misma razón, creemos, por la cual ciertos alfareros que reciben pedidos grandes y hacen ventas constantes, aún sin una necesidad económica aparente, todavía asisten todas las semanas, como han hecho durante años, a vender en el mercado local.

Así, el mercado se constituye en una red social de vital importancia para la comunidad y la venta en un intercambio gozoso de saberes. En los pueblos la venta no es ganancia y competencia, sino intercambio y conexión. Cuando una tradición alfarera desaparece, no solo se afecta su economía, se afecta también una red que articula relaciones intercomunitarias. Estas redes son mantenidas por algo sumamente frágil y sutil.

San Marcos Tlapazola es un pueblo rural donde muchas de las mujeres se dedican al barro rojo. Recientemente el pueblo organizó una feria para vender y promover sus productos. Unas cincuenta mujeres mostraban sus piezas de barro a lo largo de muchas mesas conectadas una con otra en forma de herradura. El acomodo hacía imposible ver, a primera vista, las diferencias entre una y otra alfarera. No había letreros ni marcas que individualizaran la producción. A los ojos del visitante, lo que se presentaba en esa feria era la producción del pueblo.

De nuevo, prácticas que pensadas desde la mentalidad ordinaria de la competencia comercial carecen de sentido, pues surgen de valorar la unidad comunitaria y la historia colectiva, poniéndola por encima del logro individual, este último tan enraizado en las prácticas del star system del Diseño donde el diseñador lucha por convertirse en marca registrada.

La alfarería forma parte de un sistema agrícola que tiene al maíz como columna vertebral. Es la milpa -el asombroso método de cultivo que equilibra maíz, calabaza, frijol y chile en un mismo terreno- el sistema mesoamericano que nos da de comer, y la alfarería la que transporta los alimentos a la cocina y a nuestros estómagos. El barro es testimonio vivo de la civilización mesoamericana. Es imposible entender el barro sin la gastronomía local, sin el maíz que se lava en pichanchas (coladores), las tortillas que se calientan en comales, los frijoles que se cuecen en ollas, o el agua almacenada en tinajas. El alfarero da vida a la tierra, ya que crea objetos que, a su vez, sustentan la vida. La alfarería también es diseño. Es diseño lento (slow design), muy lento, de hecho. Es diseño inteligente, adaptado con perfección a través de los siglos a su función, su cultura y a los materiales locales de producción. El barro es una tecnología suave, cada pieza es resultado de un entendimiento sofisticado de la física del material y el fuego para crear objetos funcionales de bajo impacto, en las cuales cada parte y cada aspecto cumplen una función específica. Nada, o casi nada, en estas piezas es fortuito o producto del capricho. Es diseño de escala humana: sus formas se amoldan, se adecuan al cuerpo humano, pues provienen del cuerpo humano. Es el cuerpo humano el que marca las posibilidades y los límites, tanto de la forma como de la producción. El traba- 
jo del artesano pone en marcha la memoria del cuerpo, que se guía por un saber no intelectualizado, sino sensible. El conocimiento acumulado de generaciones en generaciones se hospeda en el cuerpo y se vive a través del cuerpo.

Mis manos son mi torno, Mis manos son mi herramienta,

Mis manos me guian, Mis manos saben.

Alberta Mateo

El diseño de las formas en la alfarería no es resultado del esfuerzo heroico o el golpe de genialidad de un autor individual. Surge de la acumulación de conocimiento empírico de generaciones de artesanos, su autoría es colectiva. En la era del Diseño ecológico, verde o sustentable, la alfarería nos aporta lecciones milenarias y profundas sobre equilibrio ambiental. A diferencia de lo que sucede con la producción industrial o incluso semindustrial, los alfareros tradicionales conocen bien el peso de su huella ecológica, pues literalmente cargan los materiales, el barro y la leña, en su espalda. También saben lo que está en juego si los recursos se pierden y tienen a la vista el impacto de sus creaciones. En su caso no hay externalización del impacto en el medio ambiente. La producción de alfarería genera un mínimo de desechos (humo y cenizas). Cuando una pieza se rompe simplemente se reintegra a la tierra de donde vino. Hasta donde sabemos, la alfarería, en sus veinte mil años de existencia, nunca ha puesto en peligro la vida en la tierra -como sí lo está haciendo el plástico en pocas décadas-. La alfarería es posiblemente una de las actividades productivas más sustentables y respetuosas del medio ambiente. La alfarería tradicional está también íntimamente ligada a los ciclos de la agricultura. Su producción se alterna con los procesos de siembra y cosecha. La relación entre campo y barro es estrecha y multidimensional.

Desde el punto de vista del equilibrio social, hay también lecciones importantes que escuchar y que se contraponen a las dinámicas de trabajo asalariado y alienante de nuestros tiempos.

Los alfareros tradicionales -casi siempre mujeres- son madres, hijas, cocineras, campesinas, líderes $y$, por momentos, alfareras. Son parte integral y participan activamente en su comunidad y su familia. En su mundo, la familia y la comunidad tienen la misma importancia que los logros profesionales y el ingreso.

"Si bien la alfarería puede ser la fuente principal de ingreso, no necesariamente es la fuente de identidad más importante, ni tampoco lo que absorbe todas sus energías, por eso cada fase de la vida tiene su tiempo. Hay muchas cosas igualmente importantes" (Mindling, 2012)

En su mayoría, los artesanos son parte de una organización social sofisticada, basada en la comunidad y el respeto: "Su oficio está en armonía con los ciclos de su vida personal, familiar y comunitaria" (Mindling, 2012).

Por último, es importante notar que la belleza del barro no es una característica añadida como plusvalía mercantil, sino un aspecto intrínseco de la creación; las consideraciones estéticas están implícitas desde el inicio del proceso productivo. El barro es una fuente de orgullo e identidad. Es un trabajo que se hace por amor y un don que en muchos casos se comparte desde la profundidad de las historias da cada alfarero o alfarera. 
Figura 4. Elia Mateo Martínez, alfarera de San Marcos Tlapazola, 2017. Foto: Eric Mindling.

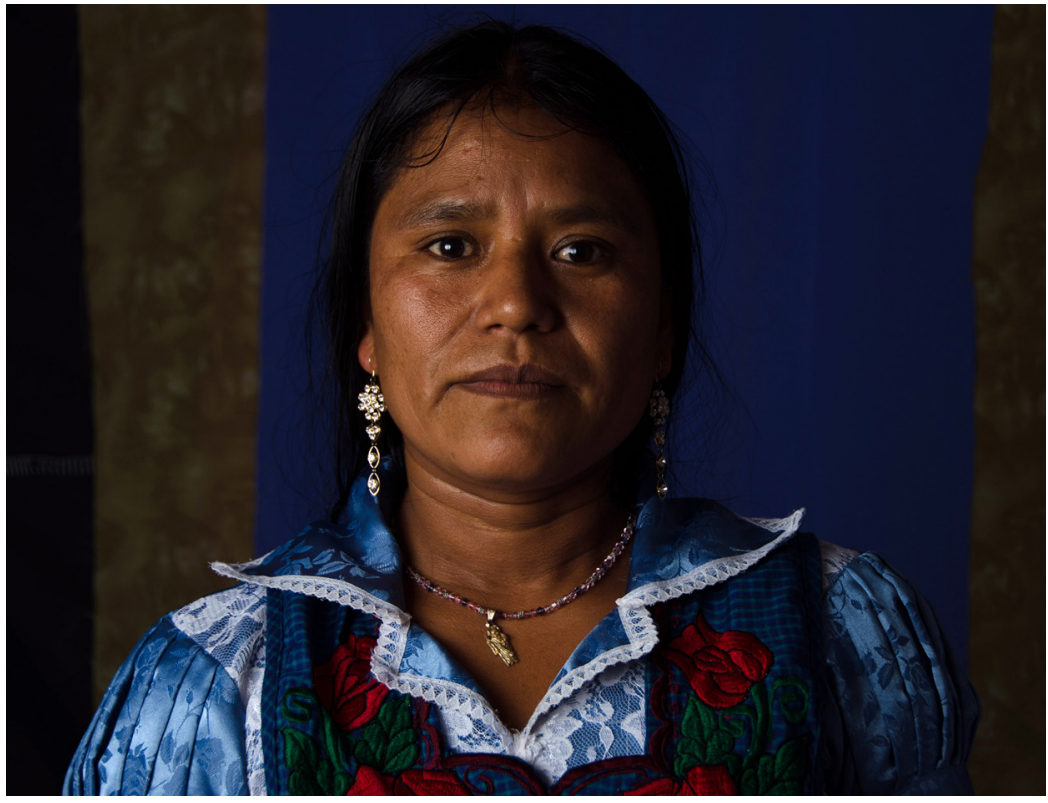

Elia Mateo, joven maestra alfarera de San Marcos Tlapazola, un pueblo zapoteco, sintetiza estas ideas, al responder a la pregunta de por qué continúa trabajando el barro y qué la ayuda a seguir:

Lo que hago es hacer mi trabajo con amor. Porque eso fue lo que mi mamá me ha inculcado, el bello trabajo que mi mamá me ha heredado. Pues yo no tengo otra cosa más que agradecer a la vida, de que mis manos puedan formar una pieza y detrás de esa pieza pues existan historias. Aparte, la felicidad que le inculca a mi trabajo. [...] me siento muy orgullosa de mis raíces, de ser una mujer indígena y aparte zapoteca. [...] Otra cosa también, trabajar el barro es muy bonito. Es algo que nos llena de mucha emoción, de mucho amor.

Mi familia, mi difunta abuelita, mis difuntas abuelitas. Ellas fueron quienes le enseñaron eso a mi señora madre. Gracias a ellas, ella me lo enseñó.

Yo estoy agradecida de los años que he vivido con el barro y sigo viviendo con el barro, de tener mis manos metidas en el barro. A veces el barro ha sido mi mejor amigo, sigue siendo mi mejor amigo, el barro me comprende, el barro puede sentir, el barro sigue vivo. Uno puede salvarse con el barro. A veces tenemos preocupaciones, pero platicándonos en silencio, pues el barro nos comprende, el barro puede sentir todo lo que sentimos. Eso a mí me satisface como mujer, como artesana que soy, eso es lo que les voy a decir.

\section{Erosión}

El valor real de la alfarería, de la "artesanía" o el diseño vernáculo, no reside en la mera técnica o la materia prima. Tampoco debe entenderse como valor añadido a productos de consumo, ni como recurso apropiable para diseñadores deseosos de participar en el mercado de productos de lujo hechos a 

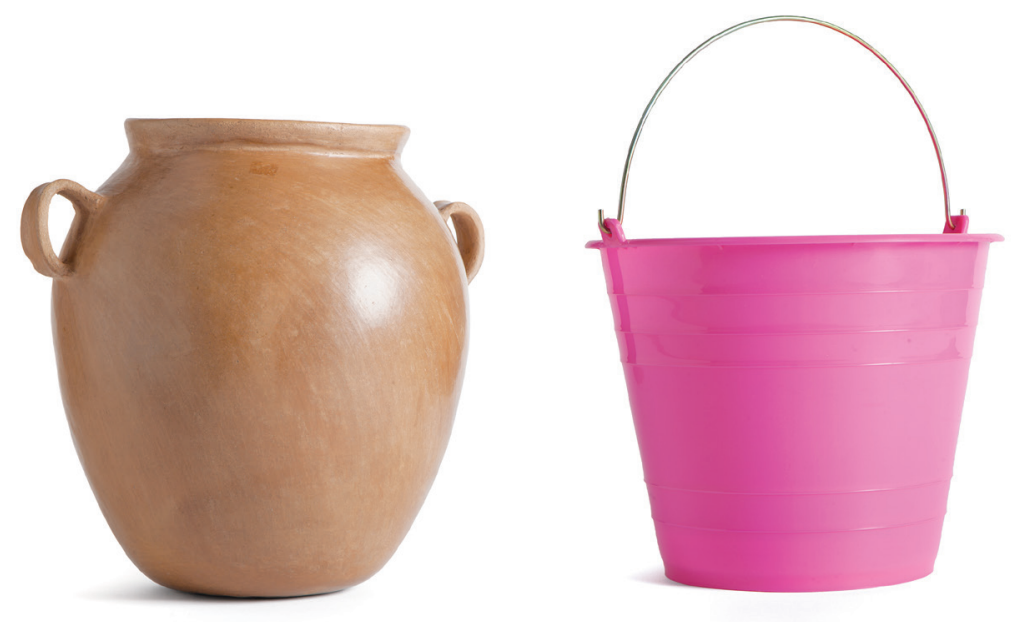

mano, ni como folclor nostálgico administrado por las instituciones de gobierno. El valor de la alfarería está en las formas de vida que la hacen posible y lo que estas nos enseñan sobre narrativas alternativas a la dominante.

Creemos además que la artesanía nos recuerda un poder básico que nos hace humanos: el del saber hacery el de hacer con las manos. Nos conecta con la habilidad humana de proyectar y de designar una función para un objeto o una herramienta, de construirla por uno mismo a partir de saberes y materias primas locales. Estas habilidades están en el origen del Diseño. Por eso cuando hablamos de alfarería hablamos de sabiduría. Los saberes de la artesanía son apropiados, a escala, conectados con su entorno, con necesidades reales, con el cuerpo y el espíritu. Son saberes que fortalecen la autosuficiencia y la autodeterminación de los pueblos y las personas. Resulta casi imposible transmitir lo que esto significa a través de un texto, sin la vivencia directa. Si lo importante es el contexto y las formas de vida que hacen posibles estos saberes, que hacen posible el surgimiento de estos objetos, entonces lo importante es crear las condiciones que posibilitan aprender con las manos y hacer con las manos, las condiciones para que la gente pueda diseñar por sí misma sus objetos, su entorno y su vida.

Ahora bien, los contextos, las formas de nombrar el mundo y de relacionarse con este, que hacen de la artesanía una actividad lógica y posible, desaparecen aceleradamente. A excepción de unos pocos, en la mayoría de los pueblos de Oaxaca la alfarería está desapareciendo, erosionándose rápidamente junto con las culturas que le dan vida, sus lenguas, sus costumbres, sus ritos, su autonomía y su territorio.

En nuestro libro Barro y Fuego mapeamos setenta pueblos que se dedican a la alfarería en el estado de Oaxaca y sus alrededores. De estos, identificamos al menos treinta pueblos cuya tradición desaparecerá en los próximos diez o veinte años, junto con la última generación (Mindling, 2012): La situación precaria en la que los saberes artesanales se encuentran no se da por falta de diseño. Identificamos seis causas de la desaparición de la alfarería, asociadas al desarrollo hiperindustrial, los sistemas de despojo territorial y cultural, la colonización comercial y cultural.
Figura 5. Olla de barro bruñido de los Reyes Metzontla, Puebla, y cubeta de plástico. Imagen del libro Barroy Fuego (2019). Fuente: Innovando la Tradición. 
1. La invasión masiva de productos de plástico y aluminio, en su mayoría importados.

2. La reducción acelerada del mercado para productos locales y tradicionales, por causas diversas.

3. La falta de interés de las nuevas generaciones.

4. La migración del campo a la ciudad o a los EUA.

5. La influencia nociva de los apoyos gubernamentales y la "industria de la ayuda", que incluye onG y diseñadores de buena voluntad, pero con nulas o pobres metodologías.

6. La narrativa que las instituciones dominantes perpetúan, aquella que ve a la tierra y el barro como algo sucio e indeseable, a los saberes tradicionales como anacrónicos, y a la vida rural como aquello a superar.

\section{Diseñadores y artesanos}

El mal llamado "rescate" o revitalización de la artesanía no se dará, como muchos pretenden, con la comercialización de productos artesanales a los cuales se les han aplicado los códigos estéticos promovidos por los diseñadores y apreciado por el mercado urbano. Tampoco se dará por integrar y asimilar a los artesanos a un sistema de mercado que por décadas los ha asediado y desplazado.

Si los diseñadores deseamos apoyar al fortalecimiento de la artesanía, es necesario empezar por escuchar a los artesanos. Escuchar aquello que viene de lejos en la historia, aquello que habla en silencio, que no reconocemos. Para que la artesanía florezca y pueda aportar belleza y sentido al mundo, debemos reenfocar la mirada más allá de la técnica y el fetiche, para trabajar en crear las condiciones que la hacen posible. Por mencionar algunas: comunalidad, respeto al territorio, reconocimiento social, sistemas de comercio solidario o leyes que reconozcan la inequidad histórica. Un análisis detallado de estas condiciones es un trabajo pendiente que hacer con los propios alfareros y alfareras.

Debemos salir del territorio conocido del Diseño, explorar áreas fuera de este y desarrollar nuevas habilidades que nos permitan abordar de manera sistémica las causas arriba mencionadas. Necesitamos estar dispuestos a cuestionar las bases de nuestro quehacer y la red de privilegios en los que se funda, y a reconocer nuestra deuda histórica con los pueblos originarios. Debemos estar dispuestos a transformar nuestra práctica en igual o mayor medida que los cambios que impulsamos o suscitamos en las prácticas de los artesanos.

\section{Innovando la Tradición}

En los últimos quince años hemos desarrollado metodologías que nos permiten escuchar a los artesanos y ser guiados por ellos. Nuestra práctica como diseñadores se ha enfocado, más que en aportar soluciones a partir de un diagnóstico propio, en hacer nuevas preguntas que nos permitan avanzar en colectivo, y en crear las plataformas -abonar el terreno, digamos- para que estas preguntas germinen.

Por ejemplo: ¿cómo abrir espacios de escucha para que las aspiraciones, sueños y compromisos reales de los artesanos sean la pauta de nuestro trabajo? ¿Cuál debe ser nuestro papel en la renovación y fortalecimiento de una tradición alfarera a la cual no pertenecemos pero que nos atrae? ¿Cómo contribuir al fortalecimiento y resiliencia de las comunidades que la resguardan? ¿Qué implica "mandar obedeciendo" en una colaboración artesano-diseñador? 


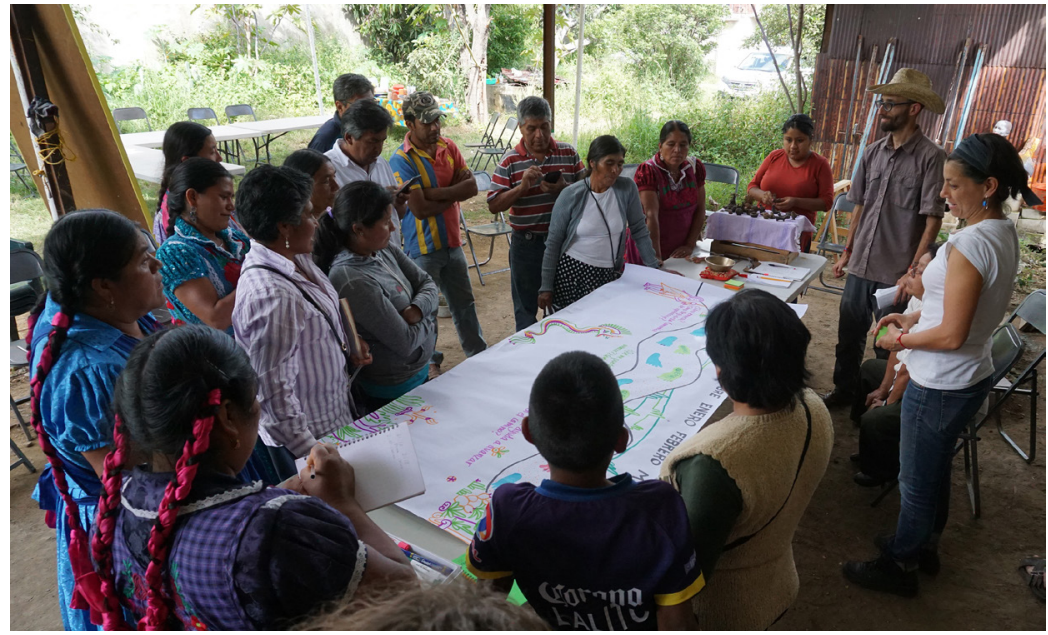

¿Cómo transformar la narrativa dominante sobre el barro, la artesanía y los saberes de los pueblos originarios? ¿Cómo crear un modelo de empresa desde los principios de la comunalidad y con objetivos primordialmente sociales? Nuestras dos organizaciones, Innovando la Tradición y el Colectivo $1050^{\circ}$ integran un híbrido, formado por una asociación civil sin fines de lucro y una cooperativa, que nos permite abordar el fenómeno de manera sistémica. Hemos tomado la milpa, el sistema agrícola mesoamericano que integra en equilibrio e interacción dinámica diversos cultivos (maíz, frijol, calabaza y chile), como la metáfora local a través de la cual estructuramos nuestro trabajo. Como los cuatro cultivos mencionados, trabajamos con cuatro principios de trabajo que se entretejen y alimentan mutuamente:

1. El aprendizaje de artesano-a-artesano que llamamos Comunidad Alfarera de Aprendizaje; 2. La Casa del Barro, como una red de espacios para transformar la percepción del barro y lo hecho a mano; 3. La necesidad de documentar, sistematizar y compartir nuestros saberes para propiciar un "crecimiento paralelo"; 4. El Colectivo $1050^{\circ}$, que aborda la dimensión comercial.

Como nos lo han indicado los alfareros, el intercambio de historias y saberes entre ellos en la Comunidad de Aprendizaje es la herramienta más poderosa para asegurar la persistencia del oficio. Desde 2017 hemos auspiciado este espacio de encuentro, basado en la confianza y la generosidad. Hemos cocreado con los artesanos un modelo de aprendizaje que incorpora herramientas de los teatros de participación, las prácticas narrativas, el diseño colaborativo y las tutorías, así como prácticas locales. Este diseño desembocó en una metodología de seis pasos que llamamos la Guelaguetza de Saberes (guelaguetza es una palabra de origen zapoteco que significa ofrenda o cooperación y se usa para designar la aportación que las personas hacen para una celebración colectiva). Nuestros encuentros integran saberes, movilizan aprendizajes y ofrecen herramientas de transformación en cuatro niveles de una montaña conceptual: en la base se encuentra La Comunidad, el encontrarnos como familia y red de apoyo, la fuerza de sentarnos en círculo para crear espacios amorosos y de confianza; después El Barro, para transformar la tierra, el agua y el fuego con nuestras manos, explorar y experimentar; más arriba está El Oficio y cómo crear relaciones sanas con la familia, el mercado o uno mismo; desde la cima
Figura 6. Una de las sesiones de la Comunidad Alfarera de Aprendizaje, 2019.

Fuente: Innovando la Tradición. 

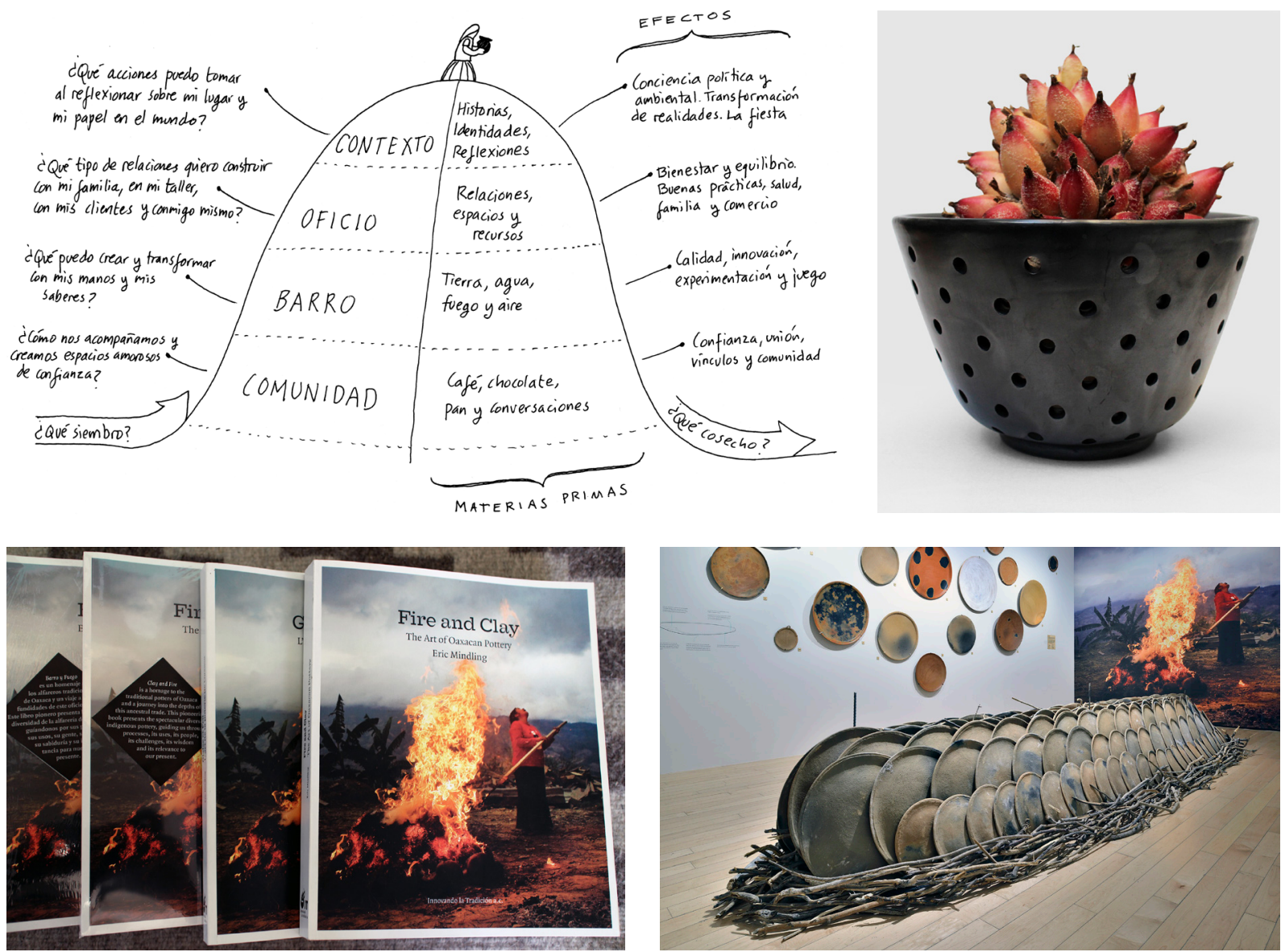

Figura 7. La "montaña de la Comunidad Alfarera de Aprendizaje", Oaxaca, 2019.

Fuente: Innovando la Tradición.

Figura 8. Frutero de barro negro bruñido, elaborado en San Bartolo Coyotepec, 2018.

Fuente: Colectivo $1050^{\circ}$.

Figura 9. Barro y Fuego, el arte de la alfarería de Oaxaca, publicado en 2012 por Innovando la Tradición, con versiones en español, inglés y francés. Fuente: Innovando la Tradición.

Figura 10. Vista de la exposición Barro y Fuego. El arte de la alfarería en Oaxaca, en el Museo Amparo, 2019. Fuente: Museo Amparo. de la montaña podemos reflexionar sobre El Contexto, transformar nuestras historias, identidades y realidades a través de la conciencia política y ambiental. El Colectivo $1050^{\circ}$ ha funcionado como el brazo comercial que hace accesible la belleza y sabiduría del barro a más personas, ofrece estabilidad económica a las familias y financia parcialmente las actividades de Innovando la Tradición. Después de diez años de posicionar la marca en el mercado y llevar barro de Oaxaca a los cinco continentes, dimos un paso adelante, casi un salto al vacío, y convertimos esta empresa social en una cooperativa donde las mismas artesanas y artesanos son los socios. Este cambio nos presenta nuevos y grandes retos legales, logísticos, organizativos y de comunicación, junto a grandes posibilidades para la creación de una comunidad de artesanos fuerte y vital que sea un ejemplo de cooperación.

Esta es posiblemente la primera cooperativa conformada por alfareros provenientes de distintos pueblos, ahora unidos por la convicción de fortalecer y defender su tradición. 


\section{Caminar fuera del mapa}

Para construir una práctica realmente significativa y apropiada al contexto local, una práctica tanto descolonizada como descolonizadora, los diseñadores debemos dejar atrás el territorio actual del Diseño, incluir sus nociones estéticas, sus metodologías positivistas, sus indicadores de éxito y sus instituciones más encumbradas.

Según el ejemplo de Henry D. Thoreau, caminemos en los terrenos desconocidos pero fértiles que existen en los márgenes del territorio. Dejemos atrás la urbe, su ética y su estética, para adentrarnos en los bosques, pantanos, desiertos y montañas de la disciplina. Reevaluemos lo anónimo, lo austero y lo pobre, lo heterogéneo y lo equívoco, lo local, lo colectivo y lo pequeño. Exploremos los territorios de lo percibido como sucio, viejo, e incluso lo indeseable. El diseñador debe "dejar de ser el autor individual de objetos o edificios, para convertirse en un posibilitador de cambios que involucren a amplios grupos de personas". Adentrémonos en el terreno difícil y complejo de lo comunal, para construir logros colectivos duraderos más allá del fugaz reconocimiento individual.

Abandonemos la falsa asepsia de la ciencia ficción y cultivemos la imaginación social, para crear nuevos futuros a partir de los saberes de quienes habitan los márgenes: los invisibles, los locos y los migrantes, los viejos, huérfanos, criminales y desplazados, y, por qué no, los animales y otros seres. Planteemos proyectos a 100, 2000300 años, en los que los resultados sean un regalo para las generaciones por venir. Atrevámonos a imaginar otros, muchos y diversos futuros que incluyan muchos y diversos mundos. Si nuestro horizonte no es el de la acumulación de capital, el crecimiento económico y el deseo sin límites, podemos remodelar nuestra práctica y concebirnos como aprendices, mediadores, organizadores comunitarios, agricultores, poetas o activistas. Creadores de nuevos lenguajes, nuevos códigos, nuevos horizontes y nuevas utopías.

\section{Referencias}

Disneyland. (1958, mayo, 14). Disney's Magic Highway [Archivo de video]. Recuperado de https://hooktube. com/TwA7C_rNbJE

Galeano, E. (1998). Patas arriba. La escuela del mundo al revés. España: Editorial Siglo XXI.

Grupo Marcuse. (2009). De la miseria humana en el medio publicitario. España: Editorial Melusina.

Mindling, E. (2012). Barro y Fuego. El arte de la alfarería en Oaxaca. México: Editorial Bom Dia Boa Tarde Boa Noite / Innovando la Tradición.

Simon, H. (1996). The Sciences of the Artificial. EUA: Editorial MIT Press.

Thackara, J. (2013). Diseñando para un mundo complejo. México: Editorial Designio. 